\title{
Changes in children's asthma prevalence over two decades in Lanzhou: effects of socioeconomic, parental and household factors
}

\author{
Suzhen Cao ${ }^{1}$, Dongsen Wen ${ }^{1}$, Sai Li ${ }^{1}$, Xiaoli Duan ${ }^{1}$, Yaqun Zhang ${ }^{2}$, Jicheng Gong ${ }^{3}$, Qian Guo ${ }^{1}$, \\ Xiangyu Xu' ${ }^{1}$, Ning Qin ${ }^{1}$, Xin Meng ${ }^{3}$, Junfeng Jim Zhang ${ }^{3,4,5,6}$
}

${ }^{1}$ Beijing Key Laboratory of Resource-oriented Treatment of Industrial Pollutants, School of Energy and Environmental Engineering, University of Science and Technology Beijing, Beijing, China; ${ }^{2}$ Gansu Provincial Design and Research Institute of Environmental Science, Lanzhou, China; ${ }^{3}$ Beijing Innovation Center for Engineering Science and Advanced Technology, State Key Joint Laboratory for Environmental Simulation and Pollution Control, College of Environmental Sciences and Engineering, And Center for Environment and Health, Peking University, Beijing, China; ${ }^{4}$ Nicholas School of the Environment and Duke Global Health Institute, Duke University, Durham, USA; ${ }^{5}$ Duke Kunshan University, Kunshan, China; ${ }^{6}$ Guangzhou Institute of Respiratory Health, The First Affiliated Hospital of Guangzhou Medical University, Guangzhou, China

Contributions: (I) Conception and design: JJ Zhang, J Gong, X Duan; (II) Administrative support: Y Zhang, S Cao; (III) Provision of study materials or patients: S Cao, Y Zhang, X Duan; (IV) Collection and assembly of data: S Li, Q Guo, X Xu; (V) Data analysis and interpretation: S Li, Q Guo, J Gong, N Qin, X Meng; (VI) Manuscript writing: All authors; (VII) Final approval of manuscript: All authors.

Correspondence to: Xiaoli Duan, PhD. University of Science and Technology Beijing, 30 Xueyuan Road, Beijing, China. Email: jasmine@ustb.edu.cn.

Background: The prevalence of childhood asthma may have changed with rapid economic development. This study aims to ascertain potential changes in asthma prevalence in relation to changes in socioeconomic, parental and household factors, based on a comparison between two periods spanning over 20 years in Lanzhou, a large northwestern city of China.

Methods: Cross-sectional studies using the same protocols were performed in Lanzhou, China in 19941995 (Period I) and in 2017 (Period II). Children of 6-12 years old from elementary schools were selected by a multistage sampling method. Information on the presence of asthma and asthma-related symptoms of children, socioeconomic status, feeding methods, parental illness and behavior patterns, as well as household characteristics, were collected through a questionnaire survey. Logistic regression models were used to estimate odds ratios of asthma prevalence with regard to socioeconomic, parental and household factors, respectively.

Results: Significant prevalence reductions were observed for paternal smoking, household coal use, and parental asthma, while the prevalence increased significantly for children sleeping in their own rooms or own beds, ventilation use during cooking, and parental occupation and education level after 22 years. In children, the prevalence of ever-diagnosed asthma decreased from 3.2\% in period I to $1.5 \%$ in Period II $(\mathrm{P}<0.001)$; the prevalence of wheeze also decreased from $15.4 \%$ to $9.3 \%(\mathrm{P}<0.001)$. Passive smoking (OR =1.531, 95\% CI: 1.032-2.270) and poor household ventilation (OR =1.709, 95\% CI: 1.208-2.416) were significantly associated with an increased prevalence of wheeze in Period I, whereas household mold (OR =2.112, 95\% CI: $1.203-$ 3.811) was significantly associated with prevalence of wheeze. Parental asthma history was associated with increased prevalence of asthma and asthma-related symptoms. Breastfeeding was significantly associated with reduced risk of asthma in period II children.

Conclusions: The prevalence of asthma and that of asthma-related symptoms were lower in 2017 than in 1994-1995 in school children living in Lanzhou. In 2017 with increased urbanization and industrialization, breastfeeding became a significant protective factor and household mold was a significant risk factor for asthma diagnosis and asthma-related symptoms. Promoting breastfeeding and household mold control is recommended to reduce the risk of childhood asthma in contemporary Lanzhou. 
Keywords: Asthma; wheeze; school children; household characteristics; parental factor; socioeconomic levels

Submitted May 17, 2020. Accepted for publication Sep 26, 2020.

doi: $10.21037 /$ jtd-19-crh-aq-008

View this article at: http://dx.doi.org/10.21037/jtd-19-crh-aq-008

\section{Introduction}

Asthma diagnosis and asthma-related symptoms (e.g., wheeze and phlegm without cold) have become one of the most common chronic childhood disorders both in developed and developing countries. In comparison with developed countries, the prevalence of asthma in China has remained low among the population in the mainland (1-3). It has shown that the prevalence of asthma has recently stabilized or even decreased in some western countries $(4,5)$. However, whether the prevalence of asthma and related symptoms elsewhere in the world has shown an increasing or decreasing trend is unclear, owing in large part to a lack of follow-up studies in these areas. Limited evidence suggests an increasing trend of asthma prevalence in China over the last 30 years $(6,7)$. Although a number of epidemiological studies have reported a higher prevalence of asthma and wheeze in the past 10 years $(3,8)$, other studies indicated a plateau or even a decline in the trend of asthma prevalence in recent years $(9,10)$.

In addition to genetic factors (11) and outdoor air pollution (12-14), there are a number of other factors that may affect the development of childhood asthma, such as socioeconomic status, passive smoking [environmental tobacco smoking (ETS)], indoor environmental conditions (including ventilation and mold, etc.), and breastfeeding. Socioeconomic status, usually defined using occupation and education level, affects respiratory health by impacting perinatal, environmental and nutritional factors, as well as accessibility to quality health care (15). Numerous studies have shown that passive smoking is associated with an increased risk for respiratory disease and symptoms $(16,17)$ and may even be a determinant of the incidence of respiratory infections (18). The indoor environment, especially in homes, has an important role in triggering and/or exacerbating asthma among children $(19,20)$, mainly due to longer time spent indoors and/or in homes $(21,22)$. Additionally, poor household ventilation (23) and mold (24) have been also among the identified risk factors for respiratory diseases including asthma and related symptoms
$(23,25)$. Some evidence suggests that breastfeeding $(26,27)$ and parental asthma history (28) could affect the prevalence of asthma in children. However, given the changes in socioeconomic level, environmental conditions and lifestyles with the rapid development of urbanization and industrialization in Chinese cities, whether the leading risk factors and the significance of those factors remain unchanged is unknown. The identification of the key factors that currently affect the prevalence of asthma and asthmarelated symptoms for children is critical to protect children's respiratory health.

A cross-sectional study was conducted to investigate the effects of air pollution, residential and parental characteristics, socioeconomic and household factors on respiratory health conditions among elementary school children in Lanzhou, China in 1994-1995 (namely Period I) $(29,30)$. With the higher level of urbanization and industrialization, most people in China have inevitably experienced a rapid change in living environment, environmental behavior pattern and lifestyle. To evaluate potential changes in the prevalence of asthma and asthmarelated symptoms, which may be associated with the rapid environmental, behavioral and socio-economical changes, a follow-up study was carried out using similar protocols in Lanzhou in 2017 (Period II). The follow-up study provides an opportunity to evaluate changes in the prevalence of asthma and asthma-related symptoms since 1994-1995 in relation to changes in socioeconomic conditions, household risk factors, and parental factors.

The objective of this study was to ascertain potential changes in the prevalence of respiratory disease in the city of Lanzhou, focusing on wheeze, phlegm without cold and self-reported doctor-diagnosed asthma and current asthma, and to examine the relationships of socioeconomic, parental and household factors with the prevalence of asthma and related symptoms.

We present the following article in accordance with the STROBE reporting checklist (available at http://dx.doi. org/10.21037/jtd-19-crh-aq-008). 


\section{Methods}

\section{Study site and participants}

The investigations in both periods were conducted in two identical urban and suburban areas (Chengguan and Xigu District, respectively) in Lanzhou, the capital city of Gansu Province, located in the northwestern region of China. Being in the transition zone between monsoon climate and nonmonsoon climate, Lanzhou has a temperate continental climate. It had a population of more than 3.7 million in 2017 , with approximately $70 \%$ urban residents (31). As an important node city in the Silk Road economic belt, Lanzhou has undergone substantial changes in population, socioeconomic and living environment due to rapid urbanization and industrialization over the past 20 years (31). In Period I, two elementary schools, one each in an urban and a suburban area, were selected. In Period II, since the two original schools of Period I were either closed or combined with other institutions, two other elementary schools as close to the site of the original schools as possible were selected.

The Period I study included 716 students from the urban area and 767 from the suburban area, while the Period II study included 848 students from the urban area and 896 from the same suburb. Students had an age range of 6 to 12 years old and participated in a questionnaire survey using a multistage sampling method. All participants in each study period were permanent residents with an at least 3-year residence history in their residential districts. Before the questionnaire survey, a written consent form was obtained from each participant and their parents or guardians, regarding the objective of the study and the main content in the questionnaire, as well as the permission for their child's voluntary participation in the survey. The study was conducted in accordance with the Declaration of Helsinki (as revised in 2013). This study was approved by the Committee on Ethics of Biomedicine Research, Duke Kunshan University, Jiangsu (No. FWA00021580). All patients enrolled completed the informed consent form.

\section{Questionnaire survey and data collection}

In both periods, information was collected via a survey of children's asthmatic and related symptoms. The survey instrument was a questionnaire consisting of respiratory health-related questions designed by the American Thoracic Society Epidemiologic Standardization Project (32) and has proved to be valid in previous study (33). Questions regarding the factors influencing respiratory diseases and symptoms were generally identical in the two periods. In Period I, we asked questions about children's sociodemographic factors, breastfeeding, history and current status of respiratory disease and symptoms of the children, parental respiratory health histories and smoking status, socioeconomic level, and household conditions. In Period II, some additions were made to reflect current conditions, such as household pets, mold, etc.

The socioeconomic class of the participants was determined based on ranked assessment of the parental occupation and highest educational qualification as described previously (34). The information on children's average physical fitness (35), including the average height and weight for different genders and ages, and the local gross domestic product (GDP) as well as the trends in regional GDP (31), over the two periods were derived from national census data. Body mass index (BMI) $\left(\mathrm{kg} / \mathrm{m}^{2}\right)$ was calculated using the weight $(\mathrm{kg})$ divided by height $(\mathrm{m})$ squared.

\section{Definition of asthma and asthmatic symptoms}

Children's respiratory disease and symptoms including doctor-diagnosed asthma, wheeze, phlegm without cold and current asthma were determined based on the following questions: (I) doctor-diagnosed asthma: 'Has a doctor ever diagnosed asthma in your child?'; (II) wheeze: 'Has your child ever had wheeze?'; (III) phlegm without cold: 'Has your child had phlegm from the chest when he/she didn't have a cold?' (IV) current asthma: 'Has your child had asthma/ in the past 12 months?'. Each question had two options, "yes" and "no," and participants were classified as having asthmatic or related symptoms when they answered "yes".

\section{Statistical analysis}

Data were tested for normality (Shapiro-Wilks $W$-test) and homogeneity (Bartlett's test for unequal variances). Continuous variables (e.g., age) were present as the mean \pm the standard deviation (SD), and categorical variables (e.g., sex) were presented as the number (percentage) in each subgroup. Two-sample $t$-tests and Pearson's chi-square $\left(\chi^{2}\right)$ tests were used to examine difference between continuous variables and between categorical variables, respectively. Univariate logistic regression models were used to examine the association between variables and the four outcome measures (wheeze, phlegm without cough, doctor-diagnosed asthma and current asthma). To identify the change in the 
contribution of independent variables on the four outcome measures, interaction analyses were calculated. Interaction terms were selected when they were statistically significant at $\mathrm{P}<0.05$. Accordingly, the interaction analyses of districts, breastfeeding and parental asthma on the association between the study period and the four outcome measures were assessed using multivariable logistic regression models and was shown with Adjusted odds ratios (ORs) with 95\% confidence intervals $(95 \% \mathrm{CI})$ after controlling various covariates (such as age, sex, district, etc.). All statistical tests were two tailed, and statistical significance was declared when a $P$ value was $<0.05$. All analyses were performed using SPSS software for Windows, version 22 (SPSS Inc., Chicago, IL, USA).

\section{Results}

\section{Characteristics of sociodemographic, household and parental factors}

In period I, a total of 1,495 questionnaires were handed out in two primary schools, and 1,483 subjects returned the questionnaires ( $99.2 \%$ response rate). In period II, a total of 2,265 questionnaires were distributed, and 2,066 $(91.2 \%)$ subjects returned the questionnaires. In order to reduce the effect caused by difference in sample size, we further randomly excluded 322 children $(15.6 \%)$ who were older boys from suburban school. Finally, we obtained a sample of 1,744 in Period II. The characteristics of the participants stratified by sociodemographic, household and parental factors, as well as the statistical difference of the characteristics, are shown in Table 1.

The average ages of the participants in Period I and Period II were 8.2 and 9.3 years, respectively. Similar to age, the average BMI of the children from Period II $\left(18.1 \mathrm{~kg} / \mathrm{m}^{2}\right)$ was statistically significantly higher than that of children from period I $\left(16.9 \mathrm{~kg} / \mathrm{m}^{2}\right)$. The urban to suburban ratio of the subjects in Period I $(0.93 \%)$ was fairly consistent with that in Period II $(0.95 \%)$, while the male to female ratio was $1.09 \%$ in Period I and $0.99 \%$ in Period II. There was no significant difference in the percentage of children who had been breastfed between the two periods. Fewer families used coal as a household fuel in Period II than in Period I (1.9\% versus 54.6\%). Ventilation during cooking had been slightly, but statistically significantly, improved from Period I to Period II. In comparison with Period I, the socioeconomic levels in Period II were higher, on the basis of the observation that there was a rapid development in regional GDP (see Figure S1). There were fewer parents of the children employed in manual professions, and more parents had a secondary or higher education in Period II. Additionally, more children had own bedrooms or own beds in Period II than in Period I. Generally, the proportion of paternal smoking was dramatically reduced from Period I to Period II (79.9\% versus $47.0 \%)$. The prevalence of paternal asthma and maternal asthma showed a decrease from Period I to Period II, for example, 9.4\% mothers suffered from asthma in Period I versus 3.0\% in Period II.

\section{Prevalence of asthma and asthmatic symptoms}

Table 2 shows the prevalence of "doctor-diagnosed" and "current" (last 12 months) reported asthma, "ever had" wheeze and "ever had" phlegm without cold in the two periods. There were no significant differences in prevalence of phlegm without cold and in prevalence of current asthma between the two periods. In contrast, wheeze was less prevalent in Period II than in Period I (9.3\% versus 15.4\%). Furthermore, the prevalence of doctor-diagnosed asthma had approximately halved from Period I to Period II (3.2\% versus $1.5 \%$ ). As shown in Table 2, the prevalence of wheeze and doctor- diagnosed asthma in children decreased from Period I to Period II.

\section{Effects of sociodemographic, housebold and parental factors on astbma diagnosis and symptoms}

Table 3 demonstrates the ORs of asthma and asthmatic symptoms associated with sociodemographic, household and parental factors in Period I and Period II, respectively. It shows that children who lived in suburban area were less likely to have wheeze and asthma, with ORs of 0.733 $(\mathrm{P}=0.032), 0.373(\mathrm{P}=0.002)$ and $0.116(\mathrm{P}=0.042)$ for wheeze, doctor-diagnosed asthma, and current asthma, respectively, in Period I. In contrast, no difference regarding the residential area distribution was observed for asthma and asthmatic symptoms in Period II. In Period I, children who lived in households without ventilation use during cooking and whose father smoked were significantly more likely to experience wheeze, with ORs of $1.709(\mathrm{P}=0.002)$ and 1.531 ( $\mathrm{P}=0.034)$, respectively. Furthermore, higher ORs of respiratory symptoms and diseases were seen for children whose parents had ever experienced asthma.

As shown in Table 3, younger children were more likely to develop current asthma, and boys were more likely to develop wheeze in Period II. However, no association 
Table 1 Sociodemographic and general information of the school children in Period I and Period II

\begin{tabular}{|c|c|c|c|c|}
\hline Category & Variables & Period I $(n=1,483)$ & Period II $(n=1,744)$ & $P$ value \\
\hline \multirow[t]{8}{*}{ Basic information } & Age & $8.2 \pm 1.73$ & $9.3 \pm 1.71$ & $<0.001$ \\
\hline & BMI & $16.9 \pm 2.26$ & $18.1 \pm 2.11$ & $<0.001$ \\
\hline & Urban & $716(48.3 \%)$ & $848(48.6 \%)$ & \\
\hline & Rural & $767(51.7 \%)$ & $896(51.4 \%)$ & \\
\hline & Male & $775(52.3 \%)$ & $870(49.9 \%)$ & \\
\hline & Female & $708(47.7 \%)$ & $874(50.1 \%)$ & \\
\hline & Breast feeding & & & 0.972 \\
\hline & No & $285(19.2 \%)$ & $336(19.3 \%)$ & \\
\hline \multirow{20}{*}{ Household factors } & No & $674(45.4 \%)$ & $1,710(98.1 \%)$ & \\
\hline & Yes & $809(54.6 \%)$ & $34(1.9 \%)$ & \\
\hline & Ventilation use when cooking & & & $<0.001$ \\
\hline & No & $237(16.0 \%)$ & $174(10.0 \%)$ & \\
\hline & Yes & $1,246(84.0 \%)$ & $1,570(90.0 \%)$ & \\
\hline & Home decoration recently & & & \\
\hline & No & - & $262(15.0 \%)$ & \\
\hline & Yes & - & $1482(85.0 \%)$ & \\
\hline & Mosquito-repellent incense use & & & \\
\hline & No & - & $774(44.4 \%)$ & \\
\hline & Yes & - & $970(55.6 \%)$ & \\
\hline & Air fresheners use & & & \\
\hline & No & - & $1,414(81.1 \%)$ & \\
\hline & Yes & - & 330 (18.9\%) & \\
\hline & Preterm birth & & & \\
\hline & No & - & 1,618 (92.8\%) & \\
\hline & Yes & - & $126(7.2 \%)$ & \\
\hline & Air purifier use & & & \\
\hline & No & - & 1,392 (79.8\%) & \\
\hline & Yes & - & $352(20.2 \%)$ & \\
\hline
\end{tabular}

Table 1 (continued) 
Table 1 (continued)

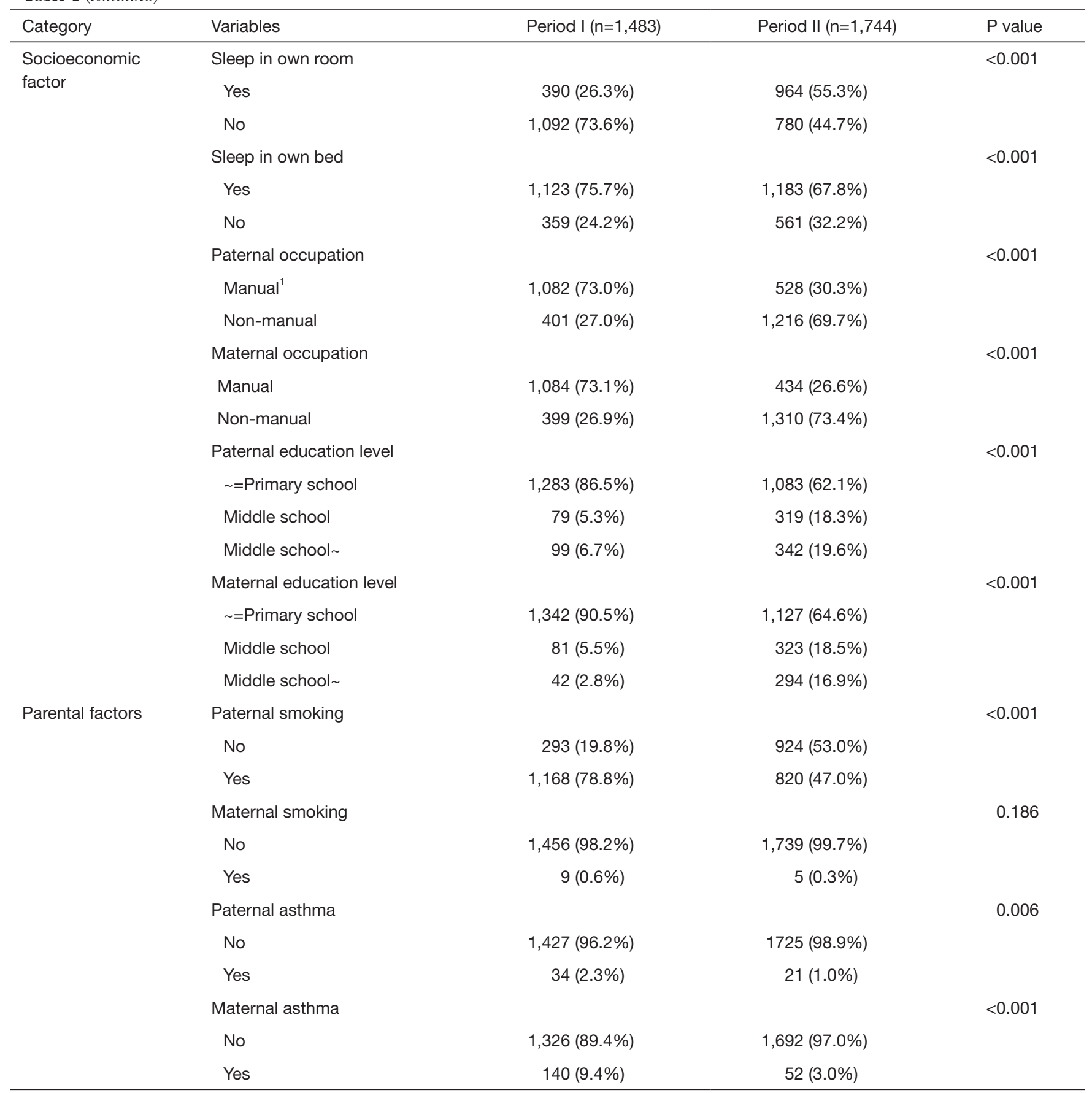

\footnotetext{
${ }^{1}$, non-manual laborer is like the so-called "white collar", such as teacher, businessperson, clerk, housewife (few cases); manual laborer is like the so-called "blue collar", such as factory worker, construction worker, building cleaning worker, farmer. = Primary school, with or above primary school; Middle school , above middle school; -, no surveyed data.
}

between ventilation use when cooking, paternal smoking, and wheezing in children was found. A protective effect of breastfeeding was observed for phlegm without cold and doctor-diagnosed asthma among breastfed children. The ORs for breastfed children were lower than those for non-breastfed children. Similarly to Period I, children 
Table 2 Prevalence of asthma and asthma-related symptoms of children in Period I and Period II, and the odds ratios (OR) and 95\% confidence interval (95\% CI) of the prevalence of asthma and asthma-related symptoms of children in Period II versus Period I

\begin{tabular}{|c|c|c|c|c|c|}
\hline Diseases and symptoms & \multicolumn{3}{|c|}{ Prevalence, N (\%) } & \multicolumn{2}{|c|}{ Odd ratios $(95 \% \mathrm{Cl})$ and $\mathrm{P}$ value } \\
\hline Wheeze & $228(15.4)$ & $162(9.3)$ & $<0.001$ & $0.440(0.279,0.694)$ & 0.001 \\
\hline Phlegm without cold & $104(7.0)$ & $116(6.7)$ & 0.685 & $0.612(0.334,1.121)$ & 0.109 \\
\hline Doctor-diagnosed asthma & $48(3.2)$ & $26(1.5)$ & $<0.001$ & $0.283(0.105,0.763)$ & 0.028 \\
\hline
\end{tabular}

Italic numbers were statistically significant.

whose fathers had ever had asthma were more likely to have current asthma $(\mathrm{OR}=18.322, \mathrm{P}<0.001)$, whereas children whose mothers had ever experienced asthma had higher ORs in wheeze, phlegm and doctor-diagnosed asthma in Period II. Furthermore, for the children who lived in a moldy household environment, the OR of wheeze was $2.112(\mathrm{P}=0.019)$.

\section{Effects of district, breastfeeding and parental asthma on children's asthma and symptoms}

To assess the change of the influence factors on children's asthma and related symptoms, the factors including district (i.e., urban and suburban), breastfeeding, paternal asthma and maternal asthma were selected based on Table 4. The interactions between each of the aforementioned factors and study period on asthma and related symptoms were examined using multivariate logistic regression analysis. The interactions between breastfeeding and study period on doctor-diagnosed asthma were statistically significant, with an OR of 0.284 (95\% CI, 0.096-0.842), indicating that breastfeeding became an important factor reducing the prevalence of children's asthma in the latter period. However, no changes of the effects of parental asthma history on children's respiratory disease and symptoms were observed.

\section{Discussion}

In this study, we assessed the changes in prevalence of asthma and related symptoms and the effects of socioeconomic, parental and household factors in children living in Lanzhou, China, on the basis of two crosssectional investigations (1994-1995 versus 2017). Generally, socioeconomic and household characteristics have improved,, parental characteristics such as the proportions of paternal smoking, were observed to be changed, after more than 20 years. The prevalence of doctor-diagnosed asthma and wheeze both decreased from the 1995-1996 period (Period I) to the 2017 period (Period II). We observed adverse effects of suburban environmental exposure, parental asthma history, paternal smoking and cooking without ventilation on the prevalence of children's asthma or symptoms in Period I. In Period II, parental asthma history was observed to be associated with the prevalence of children's asthma and/or symptoms; exposure to a moldy home environment was evidenced to increase the prevalence of wheeze. We found evidence that breastfeeding has grown more impactful as a protective factor on children having asthma after more than 20 years.

Rapid urbanization and industrialization are associated with socioeconomic development and accompanied by an increase in ambient air pollution levels. Some previous studies have demonstrated that children living in urban areas are more likely to have asthma in comparison with those living in rural or suburban areas, partly due to higher exposure to air pollution $(36,37)$. We also found that children residing in urban area had a higher prevalence of wheeze and asthma in Period I. However, the situation has substantially changed after 20 years. In general, children from urban areas in China are more socially advantaged, with better access to quality health care (38), which predisposes them to receive diagnosis and treatment more sensitively, with more attention and higher response on numerous consequences (39). Regarding the study area, Xigu was previously the center of industry in Lanzhou, while Chengguan was regarded as the center of economic and cultural life, with a large amount of vehicle emissions. Although there were significant variation in parental occupation and parental education level between 
Table 3 Adjusted odds ratios (OR) and of asthma and asthma-related symptoms in relation to socioeconomic, parental and household factors in children in Period I and Period II, respectively

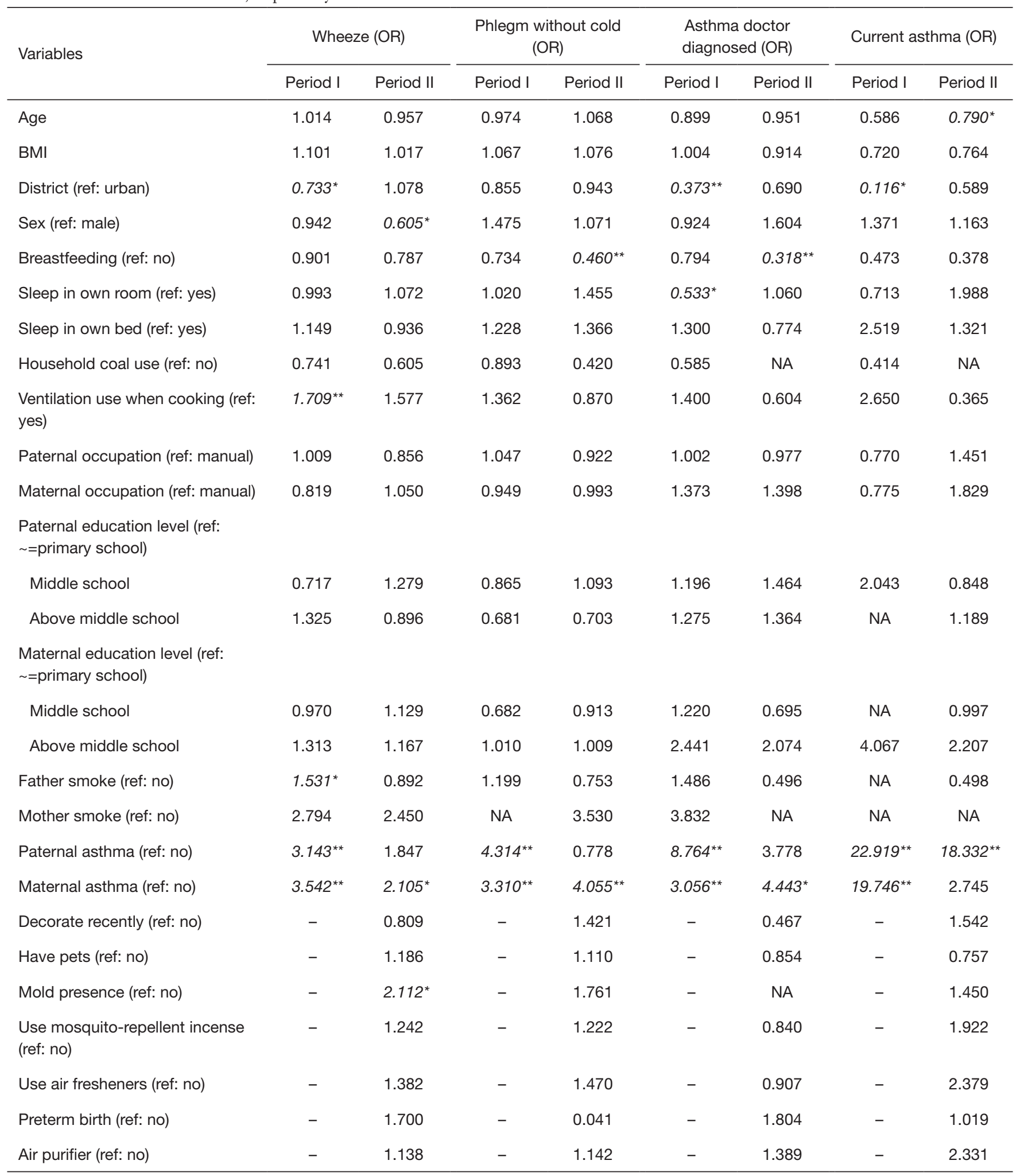

Italic numbers were statistically significant. * $\mathrm{P}<0.05 ;{ }^{\star \star}, \mathrm{P}<0.01$. NA, non-applicable; - , no data. 
Table 4 Odds ratios and 95\% confidence interval (95\% CI) of Period II versus Period I for reported asthma and asthma-related symptoms, based on multivariate logistic regression models including interactive items correlating all the confounders studied

\begin{tabular}{lcccc}
\hline Models & Wheeze & Phlegm without cold & $\begin{array}{c}\text { Doctor-diagnosed } \\
\text { asthma }\end{array}$ & Current asthma \\
\hline M0 + study phase *district & $1.282(0.726,2.263)$ & $0.808(0.388,1.682)$ & $1.971(0.582,6.680)$ & $4.978(0.356,69.533)$ \\
M0 + study phase *breastfeeding & $0.737(0.428,1.271)$ & $0.587(0.308,1.119)$ & $0.284^{*}(0.096,0.842)$ & $0.627(0.095,4.157)$ \\
M0 + study phase *parental asthma & $0.583(0.133,2.555)$ & $0.179(0.019,1.656)$ & $0.405(0.041,4.025)$ & $1.055(0.672,8.134)$ \\
M0 + study phase *maternal asthma & $0.619(0.266,1.440)$ & $1.246(0.521,2.982)$ & $1.695(0.386,7.435)$ & $0.167(0.012,2.368)$ \\
\hline
\end{tabular}

${ }^{1}$ Model 0: adjusted by age, sex, BMI, district, father smoke, mother smoke, sleep in own room, sleep in own bed, household coal use, ventilation use when cooking, paternal occupation, maternal occupation, paternal education level, maternal education level, breast feeding, paternal asthma, maternal asthma. ${ }^{*}, \mathrm{P}<0.0$. Italic numbers were statistically significant.

the two study periods, no statistically significant difference was observed in socioeconomic achievement between urban and suburban areas in Period II. Furthermore, air pollution, particularly for particulate matter, which has been shown to have adverse effects on respiratory disease and symptoms in children regardless of living in urban or suburban areas (37), showed no significant variation in recent years between urban and suburban areas (see Figure S2). These may contribute to that discrepancy of effect of district factor on the prevalence of respiratory disease and symptoms between the two periods. In agreement with our findings, a cross-sectional study conducted in Belgium also found that urban environment had no significant effects on children's wheeze (24).

Early life and long-term exposure to air pollution and low socio-economic status has been shown to promote in the development of asthma (40). Compared with Period II, in addition to parents with lower occupational and educational levels (Table 1), children in Period I were often from homes that used coal as a household fuel, were poorly ventilated, had crowed living spaces (shared room or bed), and were more likely to be exposed to indoor air pollution from using unclean fuel during cooking. This fact could be used to explain the observation that sleeping in a shared room and no ventilation use when cooking were associated with the prevalence of doctor-diagnosed asthma and wheeze, respectively, in Period I, whereas these factors were no longer significantly influential in Period II.

Reported wheezing is considered to be a reliable index of asthma (41). Previous studies have demonstrated that environmental tobacco smoke exposure is associated with an increase in the risk of respiratory diseases and symptoms $(16,17)$. We also found a significant association between the prevalence of wheezing in children and paternal smoking in Period I. Paternal smoking had no significant effect on the prevalence of wheeze, partly because of the decline in the rate of paternal smoking, or possibly because of less or no exposure for the children as more smokers tended not to smoke indoors in more recent years (42). However, we cannot conclude that ETS had no effect on children's respiratory diseases in recent years, since we neither investigated the scenarios of ETS exposure from other people or from other sites, nor quantified the amount and duration of ETS exposure.

Although the prevalence of maternal and paternal asthma in Period II were significantly lower than those in Period I, univariate logistic regression analysis showed that parental asthma (father or mother had a history of asthma) remained associated with asthma diagnosis and related symptoms for children from 1995-1996 to 2017. Furthermore, the magnitude of the effect of parental asthma on children's asthma and asthma-related symptoms did not change from Period I to Period II, based on the multivariate logistical regression analysis. The results show that parental asthma could be a strong determinant of asthma development in children. These findings strongly suggest that genetic background is an important determinant of asthma and asthma-related symptoms in children, as evidenced in a previous study (29).

Since the household mold was not surveyed in Period I, we cannot evaluate the changes in the intensity of the effect of mold on children's asthma from Period I to Period II. In Period II, we found that a moldy indoor environment was associated with a higher risk of wheeze in children, with an $\mathrm{OR}$ of $2.112(\mathrm{P}=0.019)$. The association between mold spore exposure and asthma has already been reported, and suggest that mold spores have a causal role in the development of asthma (43). A recent study conducted in Chongqing, 
China, found that home dampness and mold increased the risk of asthma (OR $=2.122,95 \%$ CI: $1.076-4.183)$ (44). A previous study on the association between airborne mold and asthma severity indicated that the size of fungal spores allows them to reach the lower airways, and they may also be inhaled by means of fragments and other amorphous bioaerosols (45). Since molds are usually present all through the year with an increase in the higher level of household indoor mold exposure particularly in fall, likely made some contribution to children's asthma because people spend most of their time indoors (23). Although we did not specify the amount and species of household indoor mold, we still can't ignore the detrimental health effects on children's asthma (43).

The effect of breastfeeding on risk of respiratory disease such as asthma has been controversial over recent years. Several prospective birth cohort studies reported that breastfeeding is not related to asthma (46), or is a risk factor for asthma rather than a protective factor $(47,48)$. However, emerging evidence suggests that breastfeeding is associated with a reduced risk of childhood asthma and asthma-related symptoms $(27,34,49)$. Usually, differences in analysis methods (34), duration of follow-up and age at which outcomes are assessed (47), whether exclusive breastfeeding (48), and breastfeeding duration (46), are suggested as partial explanations for these conflicting results. To our knowledge, breast milk is rich in immune factors, and may facilitate more effective pulmonary immune development and maturation than bottle feeding or early solid food consumption (50). Therefore, one widely accepted explanation has been that longer exclusive breastfeeding (such as $\geq 4$ months) was associated with lower rate of asthma for the children in early life of age, due to maternally derived immune factors (48). In this study, we did not specify whether the child was exclusively breastfed in both study periods. However, in Period II, the duration of breastfeeding was surveyed. After the development of more than 20 years, the experience of breastfeeding could reduce the prevalence rate of doctor-diagnosed asthma with an OR ratio of 0.284 (95\% CI: 0.096-0.842). This finding suggests breastfeeding was changed to be a protective factor for doctor-diagnosed asthma in children in recent years. With the popularization of breastfeeding knowledge and the establishment of baby-loving hospitals, the rate of exclusive breastfeeding in China is gradually increasing (51). Hence, we speculated that the higher rate of longer breastfeeding duration in Period II (i.e., $64.3 \%$ for breastfeeding $\geq 4$ months) may partly contribute to the difference in effects of breastfeeding on asthma in children. This speculation could be supported by a recent multidisciplinary review, which concluded that breastfeeding in the first 4 months of life reduced the risk of asthma (52). Furthermore, to study the protective effects of breastfeeding against other risk factors on respiratory disease, we evaluated the potential effect of interactions between breastfeeding and ETS exposure on respiratory health. In Period II, a lower rate of doctor-diagnosed asthma was found for the children with smoking fathers and breastfeeding with an OR value of 0.096 (95\% CI: 0013-0.678, as shown in Table S1), showing a modification effect of ETS exposure on respiratory disease in children, which had previously been reported in a Seven Northeast Cities Study in China (53).

With the control of confounding factors, the adjusted odds ratios of Period II versus Period I for wheeze and doctor-diagnosed asthma were 0.440 (95\% CI: 0.279-0.694) and 0.283 (95\% CI: $0.105-0.763$ ), respectively. This indicates that the prevalence of wheeze and doctor-diagnosed asthma for children decreased significantly, accompanying the socioeconomic development from 1995-1996 to 2017 in Lanzhou. Complex diseases like asthma are likely the result of interaction of exposure to environmental factors and genetic predisposition at critical times. It is established that children exposed to high levels of ambient air pollution have a higher prevalence of asthma and asthma-related symptoms (34,54). Beyond the influence of intense ambient air pollution in Period I (shown in Figure S3) which was also reported by Yin et al.,(55) the worse indoor environmental conditions in households, due to higher environmental tobacco smoke, coal use, and the less use of ventilation when cooking, contributed to the higher prevalence of asthma and symptoms for the children in Period I. Additionally, our analysis suggests that the improvement of respiratory disease for the children was partly attributable to the protective effects of breastfeeding in Period II.

The study has several limitations. First, our study design was cross-sectional, thus, we could not identify a clear temporal sequence between the exposure changes and health outcomes. However, we believe reverse causality to be improbable here, as the study was conducted in children who were matched in age and sex in the same city. Second, we did not capture data concerning indoor air pollutant concentrations, which have also been shown to affect children's respiratory health. While adjustment for ETS, household coal use, ventilation use, and parental education, likely partially mitigated confounding from indoor air pollutants, we cannot rule out residual confounding by these or other factors. Furthermore, some factors, such as 
infant feeding patterns and exposure to moldy environment, were not consistently investigated between the two study periods, which may have induced uncertain biases for the effect of influencing factors and the magnitude of the effect on respiratory disease and symptoms in our results. Regardless of these limitations, these two cross-sectional studies, with a span of more than 20 years between them, provides a valuable opportunity to examine the changes in the prevalence of asthma and asthma-related symptoms for children, as well as the changes in influencing factors and the magnitude of their effects.

\section{Conclusions}

We report a significantly lower prevalence of wheeze and doctor-diagnosed asthma in school children of Lanzhou, China in Period II [2017] compared to their age- and sex-matched counterparts in Period I [1995-1996]. Improvements in the conditions of socioeconomic status and household environment were observed along with reductions in paternal smoking rate and parental asthma prevalence after more than 20 years. In Period I, paternal smoking and less ventilation use when cooking could contribute to a higher prevalence of wheeze, while parental asthma was strongly associated with a higher rate of asthma and asthma-related symptoms. In addition to parental asthma, household mold exposure contributed to the prevalence of wheeze for children in Period II. Breastfeeding was not significantly associated with asthma and related symptoms in Period I but became an important protective factor in Period II. Based on these findings, we recommend public health policies or practices to promote breastfeeding and household mold control as strategy to reduce the burden of asthma in Lanzhou and similar cities.

\section{Acknowledgments}

We are particularly indebted to the children, their parents and the schools for their time and enthusiastic participation. We also appreciate all those who helped us during the implementation of the project.

Funding: This work was supported by the National Key Research and Development Program of China (2016YFC1302501) and the National Science Foundation (41977374, 41803016).

\section{Footnote}

Provenance and Peer Review: This article was commissioned by the Guest Editor (Junfeng Zhang, Howard Kipen and Haidong Kan) for the series "Children's Respiratory Health and Air Quality" published in Fournal of Thoracic Disease. The article was sent for peer review.

Reporting Checklist: The authors have completed the STROBE reporting checklist. Available at http://dx.doi. org/10.21037/jtd-19-crh-aq-008

Data Sharing Statement: Available at http://dx.doi. org/10.21037/jtd-19-crh-aq-008

Conflicts of Interest: All authors have completed the ICMJE uniform disclosure form (available at http://dx.doi. org/10.21037/jtd-19-crh-aq-008). The series “Children's Respiratory Health and Air Quality" was commissioned by the editorial office without any funding or sponsorship. JZ served as the unpaid Guest Editor of the series and serves as an unpaid editorial board member of Fournal of Thoracic Disease. JG serves as an unpaid editorial board member of Fournal of Thoracic Disease. The other authors have no other conflicts of interest to declare.

Ethical Statement: The authors are accountable for all aspects of the work in ensuring that questions related to the accuracy or integrity of any part of the work are appropriately investigated and resolved. The study was conducted in accordance with the Declaration of Helsinki (as revised in 2013). This study was approved by the Committee on Ethics of Biomedicine Research, Duke Kunshan University, Jiangsu (No. FWA00021580). All patients enrolled completed the informed consent form.

Open Access Statement: This is an Open Access article distributed in accordance with the Creative Commons Attribution-NonCommercial-NoDerivs 4.0 International License (CC BY-NC-ND 4.0), which permits the noncommercial replication and distribution of the article with the strict proviso that no changes or edits are made and the original work is properly cited (including links to both the formal publication through the relevant DOI and the license). See: https://creativecommons.org/licenses/by-nc-nd/4.0/. 


\section{References}

1. Lai CKW, Beasley R, Crane J, et al. Global variation in the prevalence and severity of asthma symptoms: Phase Three of the International Study of Asthma and Allergies in Childhood (ISAAC). Thorax 2009;64:476-83.

2. To T, Stanojevic S, Moores G, et al. Global asthma prevalence in adults: Findings from the cross-sectional world health survey. BMC Public Health 2012;12:204.

3. Zhang F, Hang J, Zheng B, et al. The changing epidemiology of asthma in Shanghai, China. J Asthma 2015;52:465-70.

4. Ronchetti R, Villa MP, Barreto M, et al. Is the increase in childhood asthma coming to an end? Findings from three surveys of schoolchildren in Rome, Italy. Eur Respir J 2001;17:881-6.

5. Braun-Fahrländer C, Gassner M, Grize L, et al. No further increase in asthma, hay fever and atopic sensitisation in adolescents living in Switzerland. Eur Respir J 2004;23:407-13.

6. Leung R, Wong G, Lau J, et al. Prevalence of asthma and allergy in Hong Kong schoolchildren: an ISAAC study. Eur Respir J 1997;10:354-60.

7. Bai J, Zhao J, Shen KL, et al. Current trends of the prevalence of childhood asthma in three Chinese cities: a multicenter epidemiological survey. Biomed Environ Sci 2010;23:453-7.

8. Wang WY, Lin JT, Su N, et al. Survey on the prevalence rate of bronchial asthma in Beijing area among the residents aged over 14 years from 2010 to 2011. Zhonghua Yi Xue Za Zhi 2013;93:1383-7.

9. Wong GW, Leung TF, Ko FW, et al. Declining asthma prevalence in Hong Kong Chinese schoolchildren. Clin Exp Allergy 2004;34:1550-5.

10. Khetsuriani N, Kazerouni NN, Erdman DD, et al. Prevalence of viral respiratory tract infections in children with asthma. J Allergy Clin Immun 2007;119:314-21.

11. Wong GWK, Chow CM. Childhood asthma epidemiology: Insights from comparative studies of rural and urban populations. Pediatr Pulmonol 2008;43:107-16.

12. Anderson HR, Ruggles R, Pandey KD, et al. Ambient particulate pollution and the world-wide prevalence of asthma, rhinoconjunctivitis and eczema in children: Phase One of the International Study of Asthma and Allergies in Childhood (ISAAC). Occup Environ Med 2010;67:293-300.

13. McConnell R, Islam T, Shankardass K, et al. Childhood incident asthma and traffic-related air pollution at home and school. Environ Health Perspect 2010;118:1021-6.
14. Chung KF, Zhang JF, Zhong NS. Outdoor air pollution and respiratory health in Asia. Respirology 2011;16:1023-6.

15. Kuti BP, Oladimeji OI, Kuti DK, et al. Rural-urban disparity in lung function parameters of Nigerian children: effects of socio-economic, nutritional and housing factors. Pan Afr Med J 2017;28:230.

16. Yan ML, Gong JC, Liu Q, et al. Prevalence of respiratory diseases in relation to smoking rate in adults living in four Chinese cities: A comparison between 2017-2018 and 1993-1996. J Thoracic Disease 2020. doi: 10.21037/jtd19-crh-aq-002.

17. Magnus MC, Haberg SE, Karlstad O, et al. Grandmother's smoking when pregnant with the mother and asthma in the grandchild: the Norwegian Mother and Child Cohort Study. Thorax 2015;70:237-43.

18. Lugade AA, Bogner PN, Thatcher TH, et al. Cigarette smoke exposure exacerbates lung inflammation and compromises immunity to bacterial infection. J Immunol 2014;192:5226-35.

19. Sun Y, Sundell J. Life style and home environment are associated with racial disparities of asthma and allergy in Northeast Texas children. Sci Total Environ 2011;409:4229-34.

20. Bornehag CG, Sundell J, Sigsgaard T. Dampness in buildings and health (DBH): Report from an ongoing epidemiological investigation on the association between indoor environmental factors and health effects among children in Sweden. Indoor Air 2004;14:59-66.

21. Leech JA, Nelson WC, Burnett RT, et al. It's about time: A comparison of Canadian and American time-activity patterns. J Expo Anal Environ Epidemiol 2002;12:427-32.

22. Duan XL, Wang BB, Zhao XG, et al. Highlight of the Chinese exposure factors handbook (Adults). Science Presee, Beijing 2014.

23. Sundell J, Levin H, Nazaroff WW, et al. Ventilation rates and health: Multidisciplinary review of the scientific literature. Indoor Air 2011;21:191-204.

24. Wieringa MH, Vermeire PA, Van Bever HP, et al. Higher occurrence of asthma-related symptoms in an urban than a suburban area in adults, but not in children. Eur Respir J 2001;17:422-7.

25. Zureik M, Neukirch C, Leynaert B, et al. Sensitisation to airborne moulds and severity of asthma: cross sectional study from European Community respiratory health survey. BMJ 2002;325:411.

26. Al-Makoshi A, Al-Frayh A, Turner S, et al. Breastfeeding Practice and Its Association with Respiratory Symptoms and Atopic Disease in 1-3-Year-Old Children in the 
City of Riyadh, Central Saudi Arabia. Breastfeed Med 2013;8:127-33.

27. Rosas-Salazar C, Forno E, Brehm JM, et al. Breastfeeding duration and asthma in Puerto Rican children. Pediatr Pulmonol 2015;50:527-34.

28. Dong GH, Ma YN, Ding HL, et al. Pets Keeping In Home, Parental Atopy, Asthma, And Asthma-related Symptoms In 12,910 Elementary School Children From Northeast China. Indoor Air 2009;19:166-73.

29. Zhang JJ, Hu W, Wei F, et al. Children's respiratory morbidity prevalence in relation to air pollution in four Chinese cities. Environ Health Perspect 2002;110:961-7.

30. Qian Z, Zhang JF, Wei FS, et al. Long term ambient air pollution levels in four Chinese cities: inter-city and intracity exposure gradients for epidemiologic studies. J Expo Anal Environ Epidemiol 2001;11:341-51.

31. Lanzhou Bureau of Statistics. Lanzhou Statistical Yearbook [document on the Internet]. no date [cited 2018]. Available online: http://tjj.lanzhou.gov.cn/art/2018/11/29/ art_4866_526974.html</eref>

32. Ferris BG. The American review of respiratory disease. Epidemiology Standardization Project (American Thoracic Society). Am Rev Respir Dis 1978;118:1-120.

33. Dong GH, Qian ZM, Liu MM, et al. Breastfeeding as a modifier of the respiratory effects of air pollution in children, Epidemiology 2013;24:387-94.

34. Oyedeji GA. Socioeconomic and cultural background of hospitalized children in Ilesa. Niger J Paediatr 1985;13:111-8.

35. Yao L. Analysis of the research results on the physical condition of primary and middle school students in Lanzhou. Journal of Gansu Union University: Natural Science Edition 1997;22:90-3.

36. Luo S, Sun Y, Hou J, et al. Pet keeping in childhood and asthma and allergy among children in Tianjin area, China. PLoS One 2018;13:e0197274.

37. Peng L, Xining W, Jiayin F, et al. Effects of Air Pollution on Hospital Emergency Room Visits for Respiratory Diseases: Urban-Suburban Differences in Eastern China. Inter J Env Res Pub Heal 2016;13:341.

38. UNICEF 2016 Global nutritional report. Accessed 2nd September, 2017.

39. Schaible UE, Kaufmann SH. Malnutrition and Infection: complex mechanisms and global impacts. Plos Med 2007;4:e115.

40. O'Lenick CR, Winquist A, Mulholland JA, et al. Assessment of neighbourhood-level socioeconomic status as a modifier of air pollution-asthma associations among children in
Atlanta. J Epidemiol Community Health 2017;71:129-36.

41. Wright AL, Holberg CJ, Morgan WJ, et al. Recurrent cough in childhood and its relation to asthma. Am J Respir Crit Care Med 1996;153:1259-65.

42. Liu P, Bai YN, Hu XB, et al. Logical regression analysis on influential factors of smoking behavior among urban residents in Lanzhou. Chin J Public Health 2003;29:272-4.

43. Flamant-Hulin M, Annesi-Maesano I, Caillaud D. Relationships between molds and asthma suggesting nonallergic mechanisms. A rural-urban comparison. Pediatr Allergy Immunol 2013;24:345-51.

44. Li WY, Liu Q, Chen YW, et al. Effects of indoor environment and lifestyle on respiratory health of children in Chongqing, China. J Thorac Dis 2020;10:6327-41.

45. Zureik M, Neukirch C, Leynaert B, et al. Sensitisation to airborne moulds and severity of asthma: cross sectional study from European Community respiratory health survey. British Medical Journal 2002;325:411-4.

46. Matheson MC, Erbas B, Balasuriya A, et al. Breastfeeding and atopic disease: a cohort study from children to middle age. J Allergy Clin Immunol 2007;120:1051-7.

47. Sears MR, Greene JM, Willan AR, et al. Long-term relation between breastfeeding and development of atopy and asthma in children and young adults: a longitudinal study. Lancet 2002;360:901-7.

48. Wright AL, Holberg CJ, Taussig LM, et al. Factors influencing the relation of infant feeding to asthma and recurrent wheeze in childhood. Thorax 2001;56:192-7.

49. Gdalevich M, Mimouni D, Mimouni M. Breast-feeding and the risk of bronchial asthma in childhood: a systematic review with meta-analysis of prospective studies. J Pediatr 2001;139:261-6.

50. Ballard O, Morrow AL. Human milk composition: nutrients and bioactive factors. Pediatr Clin North Am 2013;60:49-74.

51. Zhang JL. Investigation on breastfeeding attitude among postpartum women in Lanzhou and analysis of influencing factors. Lanzhou University 2019.

52. van Odijk J, Kull I, Borres MP, et al. Breastfeeding and allergic disease: a multidisciplinary review of the literature (1966-2001) on the mode of early feeding in infancy and its impact on later atopic manifestations. Allergy 2003;58:833-43.

53. Liu YQ, Qian Z, Wang J, et al. Breastfeeding modifies the effects of environment tobacco smoke exposure on respiratory diseases and symptoms in Chinese children: the Seven Northeast Cities Study. Indoor Air 2016;26:614-22. 54. Knibbs LD, Cortés de Waterman AM, Toelle BG, et 
al. The Australian Child Health and Air Pollution Study (ACHAPS): A national population-based crosssectional study of long-term exposure to outdoor air pollution, asthma, and lung function. Environ Int 2018;120:394-403.

Cite this article as: Cao S, Wen D, Li S, Duan X, Zhang Y, Gong J, Guo Q, Xu X, Qin N, Meng X, Zhang JJ. Changes in children's asthma prevalence over two decades in Lanzhou: effects of socioeconomic, parental and household factors. J Thorac Dis 2020;12(10):6365-6378. doi: 10.21037/jtd-19-crhaq-008
55. Yin Z, Huang $X, \mathrm{He} \mathrm{L}$, et al. Trends in ambient air pollution levels and PM2.5 chemical compositions in four Chinese cities from 1995 to 2017. J Thorac Dis 2020:12:6396-410. 


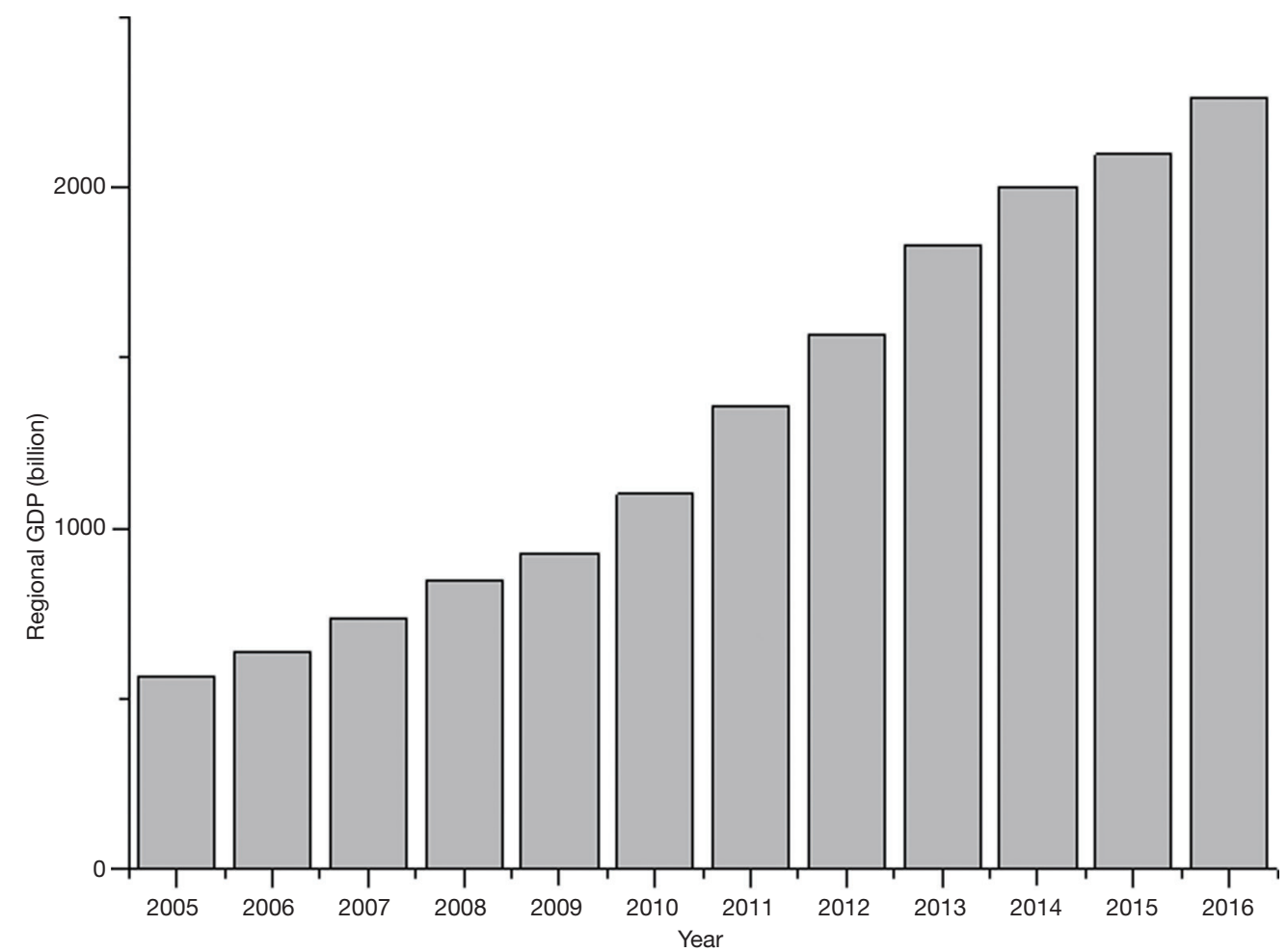

Figure S1 Annual gross regional product in Lanzhou city from 2005-2016 (data was obtained from the National monitoring station data released by the Ministry of Ecology and Environment).

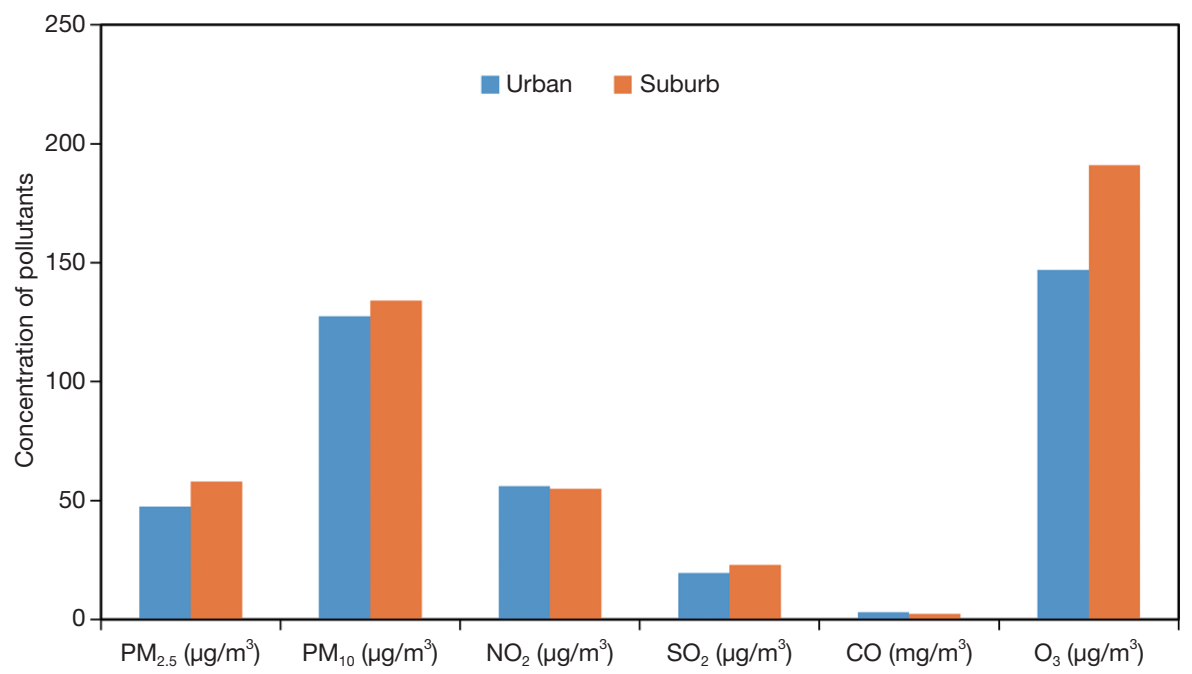

Figure S2 Concentrations of major atmospheric pollutants in urban and suburban areas in Lanzhou in 2017 (data was obtained from the National monitoring station data released by the Ministry of Ecology and Environment). 
Table S1 The odds ratios (95\% CI) of father smoke *breastfeeding in two periods for reported asthma and related symptoms according to multivariate logistic regression models correlating all the confounders studied

\begin{tabular}{lcccc}
\hline Interactions & Wheeze & Phlegm without cold & $\begin{array}{c}\text { Asthma doctor } \\
\text { diagnosed }\end{array}$ & Current asthma \\
\hline Period 1 & & & & \\
Father smoke *breastfeeding & $1.037(0.401,2.682)$ & $1.110(0.337,3.660)$ & $1.978(0.331,11.834)$ \\
Mother smoke *breastfeeding & $0.961(0.046,19.905)$ & $\mathrm{NA}$ & $\mathrm{NA}$ & $\mathrm{NA}$ \\
$\begin{array}{l}\text { Period 2 } \\
\text { Father smoke *breastfeeding }\end{array}$ & $0.806(0.365,1.780)$ & $1.139(0.485,2.678)$ & $0.096 *(0.013,0.678)$ & $2.126(0.144,31.304)$ \\
Mother smoke *breastfeeding & $\mathrm{NA}$ & $\mathrm{NA}$ & $\mathrm{NA}$ & $\mathrm{NA}$ \\
\hline
\end{tabular}

*, $\mathrm{P}<0.05$. Adjusted by age, sex, BMI, district, father smoke, mother smoke, sleep in own room, Sleep in own bed, household coal use, ventilation use when cooking, paternal occupation, maternal occupation, paternal education level, maternal education level, breast feeding, paternal asthma, maternal asthma. Italic numbers were statistically significant.
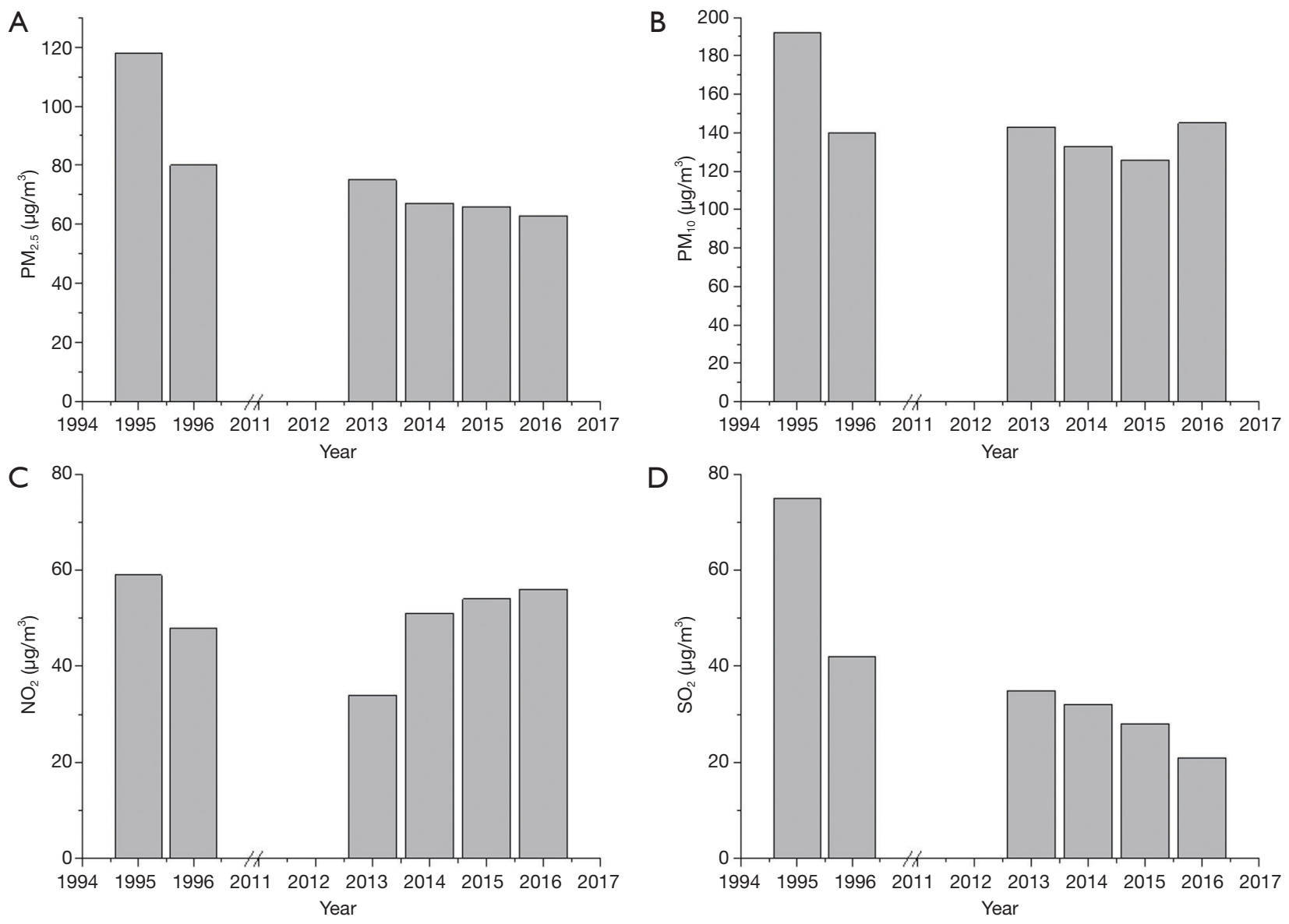

Figure S3 Annual means of (A) fine particulate matter $\left(\mathrm{PM}_{2.5}\right),(\mathrm{B})$ particulate matter $\left(\mathrm{PM}_{10}\right),(\mathrm{C})$ nitrogen dioxide $(\mathrm{NO})_{2}$ and $(\mathrm{D})$ sulfur dioxide $\left(\mathrm{SO}_{2}\right)$ concentrations for the period 1995-1996 and 2013-2016 (data was obtained from the National monitoring station data released by the Ministry of Ecology and Environment). 